\title{
PERAN DINAS SOSIAL DALAM PEMBERDAYAAN MASYARAKAT MELALUI PROGRAM KELUARGA HARAPAN (PKH) UNTUK PENANGGULANGAN KEMISKINAN DI DESA SIDIANGKAT KECAMATAN SIDIKALANG KABUPATEN DAIRI
}

\author{
Mohd Iqbal Abdul Muin, Siti Abidah Lubis \\ Fakultas Dakwah dan Komunikasi \\ Universitas Islam Negeri Sumatera Utara \\ Email: mohIqbal@gmail.com
}

\begin{abstract}
Abstrak
Tujuan penelitian ini untuk mengetahui bentuk kegiatan Dinas Sosial dalam pelaksanaan pemberdayaan masyarakat melalui Program Keluarga Harapan (PKH), untuk mengetahui hambatan pemerintah melaksanakan pemberdayaan masyarakat melalui Program Keluarga Harapan (PKH), danuntuk mengetahui solusi pemerintah dalam melaksanakan pemberdayaan masyarakat melalui Program Keluarga Harapan (PKH). Metode yang digunakan dalam penelitian ini adalah metode kualitatif, dengan mengumpulkan data lapangan dengan menggunakan cara observasi, wawancara, dan dokumentasi. Adapun yang menjadi informan dalam penelitian ini adalah Dinas Sosial dan masyarakat yang mendapat bantuan melalui Program Keluarga Harapan. Berdasarkan hasil penelitian, kehadiran dan peran Dinas Sosial melalui Program Keluarga Harapan (PKH) di Desa Sidiangkat berjalan sesuai dengan tujuannya untuk mengentaskan kemiskinan dan meningkatkan kualitas sumber daya manusia pada kelompok masyarakat yang sangat miskin dengan memberikan pelayanan kesehatan, pelayanan pendidikan, dan pelayanan kesejahteraan sosial kepada masyarakat yang miskin. Dalam meningkatkan kesejahteraan masyarakat, pemerintah mengalami beberapa hambatan dalam pemberdayaan masyarakat melalui Program Keluarga Harapan diantaranya adalah pendataan kependudukan masyarakat miskin yang tidak lengkap sehingga menjadi kendala bagi pihak PKH dalam meratakan pemberian penerima bantuan $\mathrm{PKH}$, kurangnya pemahaman masyarakat mengenai Program Keluarga Harapan.
\end{abstract}

Katakunci: Peran Dinas Sosial; Pemberdayaan Masyarakat; Penanggulangan Kemiskinan; Program Keluarga Harapan (PKH)

\section{PENDAHULUAN}

Kesejahteraan pada umumnya merupakan dambaan bagi setiap manusia yang hidup didunia.Tidak ada satu manusia pun yang lahir kedunia ini ingin hidup dalam keadaan miskin pastilah semua ingin hidup sejahtera.Yang dimaksud dengan kesejahteraan adalah keamanan dan keselamatan hidup yakni konsep yang menunjukkan keadaan, dimana setiap orang, baik sebagai individu maupun sebagai anggota masyarakat dapat memenuhi kebutuhannya karena tersedianya barang dan jasa yang dapat diperoleh dengan harga yang relatif murah.Dengan

Mohd Iqbal Abdul Muin, Siti Abidah Lubis|

Peran Dinas Sosial dalam Pemberdayaan Masyarakat melalui Program Keluarga Harapan (PKH) untuk Penanggulangan Kemiskinan di Desa Sidiangkat Kecamatan Sidikalang 
demikian yang dimaksud dengan kesejahteraan adalah keadaan orang yang hidup aman dan tentram serta dapat memenuhi kebutuhan hidupnya.

Kesejahteraan dalam konsep Islam menurut Imam Al-Ghozali terpenuhinya 5 (lima) unsur pokok yaitu demi menjaga keyakinan agamanya, memelihara jiwanya, keturunannya, harta bendanya serta akal atau fikirannya. Islam sangat menganjurkan kepada ummatnya agar selalu berusaha demi meningkkatkan kesejahteraan hidupnya.Dalam hal ini Allah menegaskan didalam Al-Quran surah Ar-Rad ayat 11 yang berbunyi :

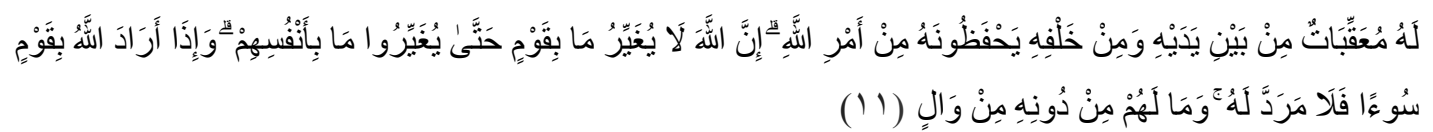

Artinya :"Bagi manusia ada malaikat-malaikat yang selalu mengikutinya bergiliran, di muka dan dan di belakangnya, mereka menjaganya atas perintah Allah. Sesungguhnya Allah tidak merobah keadaan sesuatu kaum sehingga mereka merobah keadaan yang ada pada diri mereka sendiri, dan apabila Allah menghendaki keburukan terhadap sesuatu kaum, Maka tak ada yang dapat menolaknya, dan sekali-kali ada perlindungan bagi mereka selain Dia".

Salah satu program bantuan itu ialah seperti Program Keluarga Harapan (PKH) yang berada di Desa Sidiangkat.Program Keluarga Harapan ini merupakan program perlindungan sosial yang memberikan bantuan tunai kepada Rumah Tangga Sangan Miskin (RTSM) dengan persyaratan tertentu.Tujuan dari program ini adalah mengentaskan angka dan memutus rantai kemiskinan, meningkatkan kualitas sumber daya manusia, serta merubah perilaku yang kurang mendukung peningkatan kualitas sumber daya manusia, serta merubah perilaku yang kurang mendukung peningkatan kesejahteraan dari kelompok paling miskin. Secara khusus, tujuan PKH terdiri atas : Meningkatkan kondisi sosial ekonomi RTSM, meningkatkan taraf pendidikan anak-anak RTSM, meningkatkan status kesehatan dan gizi ibu hamil dan kualitas pelayanan pendidikan dan kesehatan, khususnya bagi RTSM.

Dalam pelaksanaan PKH, terdapat peran Dinas Sosial yang menjadi aktor dalam menyukseskan PKH.Dinas Sosial yaitu suatu unit pemerintahan dibidang sosial yang mengurus suatukegiatan profesional untuk membantu individu-individu, kelompokkelompok dan masyarakat guna meningkatkan atau memperbaiki kemampuan mereka dalam berfungsi sosial serta menciptakan kondisi masyarakat yang memungkinkan mereka mencapai tujuan. 
Peran Dinas Sosial tidak jauh beda dengan peran pekerjaan sosial lainnya, yaitu membantu orang meningkatkan dan menggunakan kemampuannya secara efektif untuk melaksanakan tugas-tugas kehidupan dan memecahkan masalah-masalah sosial yang mereka alami. Di dalam Peran Dinas sosial ini, ada program pemerintah yang dapat langsung turun ke masyarakat yaitu Program Keluarga Harapan (PKH).

Program Keluarga Harapan merupakan program dari pemerintah yang pelaksanaannya pun masih belum melalui proses dan tahapan perencanaan, pengorganisasian, penggerakan, dan evaluasi. Selain manajemen yang baik, peran Dinas Sosial sangat perlu diperhatikan dalam program ini, karena melalui peran ini dapat diketahui seberapa tolak ukur pencapaian program.

Untuk mencapai tujuan tersebut, perlu diciptakan suatu program pemberdayaan di pedesaan sehingga mampu mensejahterakan keluarga dan masyarakat melalui Program Keluarga Harapan untuk penanggulangan kemiskinan.Dalam hal ini diperlukan pembinaanpembinaan oleh lembaga-lembaga pemerintah maupun instansi terkait kepada masyarakat dalam upaya kesejahteraan dan kualitas hidupnya.

Berdasarkan uraian yang telah dikemukakan, maka bisa ditarik sebuah rumusan masalah yang nantinya akan dibahas dalam penelitian ini yang akan dilakukan bisa terarah dan fokus dalam kajian yang diteliti. Adapun rumusan masalahnya sebagai berikut :

1. Bagaimana kegiatan Dinas Sosial dalam pemberdayaan masyarakat melalui program keluarga harapan di Desa Sidiangkat Kecamatan Sidikalang Kabupaten Dairi?

2. Bagaimana hambatan Dinas Sosial dalam pemberdayaan masyarakat melalui program keluarga harapan di Desa Sidiangkat Kecamatan Sidikalang Kabupaten Dairi?

3. Bagaimana solusi pemerintah Dinas Sosial dalam pemberdayaan masyarakat melalui program keluarga harapan di Desa Sidiangkat Kecamatan Sidikalang Kabupaten Dairi?

Terkait penelitian yang dilakukan terdapat penelitian-penelitian terdahulu diantaranya :

1. Penelitian yang dilakukan oleh Evi Rahmawati Jurusan Pendidikan Nonformal Fakultas Ilmu Pendidikan Universitas Negeri Semarang pada tahun 2017 yang berjudul "Peran Pendamping Dalam Pemberdayaan Masyarakat Miskin Melalui Program Keluarga Harapan Di Kecamatan Semarang Tengah." Tujuan dari penelitian ini adalah untuk mendeskrispsikan peran pendamping program keluarga harapan (PKH) dan untuk mendepenelitiankan faktor pendukung dan penghambat peran pendamping dalam 
pendampingan program keluarga harapan $(\mathrm{PKH})$. Peneliti juga menyimpulkan bahwa peran pendamping terbagi menjadi empat diantaranya adalah : 1) Peran dan keterampilan fasilitatif, bahwa pendamping telah melakukan perannya sebagai fasilitator dengan membantu informasi, motivasi serta membantu pengorganisasian peserta PKH yang sangat dibutuhkan untuk peserta PKH. 2) Pendamping telah memenuhi perannya sebagai pendidik. Hal yang dilakukan pendamping sebagai pendidik yaitu pada saat pertemuan kelompok Family Development Sessions (FDS). 3) Peran dan keterampilan representasi/perwakilan masyarakat dengan mendatangi layanan-layanan eksternal seperti puskesmas, posyandu, dan sekolah untuk kepentingan peserta PKH. Pada pendamping di Kecamatan Semarang Tengah juga menemukan kendala-kendala. Faktor Internal yang mnjadi kendala dalam pendampingan adalah sulitmya peserta untuk mengumpulkan berkas dana atu formulir pemutakhiran. Selain itu untuk beradaptadi dengan lingkungan baru pendamping memerlukan waktu. Selain faktor penghambat, ada pula faktor pendukung dalam proses pendampingan meliputi dukungan dari masyarakat penerima bantuan dan ibu-ibu yang rajin hadir. Serta alat bantu pendampingan berupa buku yang berisi materi yang sangat membantu dalam penyampaian Family Development Sessions (FDS). ${ }^{1}$

2. Penjelasan penelitian terdahulu peneliti paparkan sebagai pembanding untuk penelitian yang dilakukan saat ini sehingga menjadi referensi dan pembanding untuk penelitian penelitian ini berbeda dengan kedua penelitian yang dipaparkan oleh peneliti diatas, penelitian ini membahas Peran Dinas Sosial Dalam Pemberdayaan Masyarakat Melalui Program Keluarga Harapan (PKH) Untuk Penanggulanan Kemiskinan Di Desa Sidiangkat Kecamatan Sidikalang Kabupaten Dairi dan berfokus kepada sosial ekonomi

\section{METODE PENELITIAN}

\section{Lokasi Penelitian}

Penelitian ini dilaksanakan di salah satu desa yang bertepatan Di Desa Sidiangkat Kecamatan Sidikalang Kabupaten Dairi.Alasan penelitian memilih lokasi ini adalah karena kegiatan ini berperan untuk penanggulangan kemiskinandalam pemberdayaan masyarakat melalui Program Keluarga Harapan $(\mathrm{PKH})$ sehingga peneliti merasa tertarik untuk melaksanakan penelitian di lokasi tersebut.

\footnotetext{
${ }^{1}$ https://lib.unnes.ac.id/29800/1/1201413087.pdf (diakses pada 082017 pukul 14:10) 


\section{Pendekatan Penelitian}

Pendekatan penelitian ini menggunakan pendekatan penelitian kualitatif. Penelitian yang dilakukan berupaya mendepenelitiankan bentuk pelaksanaan pemberdayaan masyarakat melalui Program Keluarga Harapan $(\mathrm{PKH})$ untuk penanggulangan kemiskinan di Desa Sidiangkat Kecamatan Sidikalang Kabupaten Dairi.

\section{Subjek Penelitian}

Subjek penelitian pada penelitian ini adalah para anggota yang melakukan Program Keluarga Harapan (PKH) dalam pemberdayaan masyarakat untuk penanggulangan kemiskinan. Selain itu ada informasi pelengkap yaitu warga yang mengikuti Program Keluarga Harapan untuk penanggulangan kemiskinan di Desa Sidiangkat, Kecamatan Sidikalang, Kabupaten Dairi. Jumlah subjek penelitian ditentukan oleh pertimbanganpertimbangan informasi yang diperlukan.

\section{Teknik Pengumpulan Data}

Untuk memperoleh data yang dibutuhkan dalam penelitian ini maka peneliti mempergunakan beberapa alat pengumpulan data, adapun alat pengumpulan data tersebut adalah :

1. Wawancara merupakan salah satu teknik yang dapat digunakan untuk mengumpulkan data penelitian. Proses wawancara dilakukan dalam lima tahapan:

a) Menentukan informasi yang akan diwawancarai

b) Mempersiapkan kegiatan wawancara, daftar wawancara, sifat perttanyaan, alat bantu, menyesuaikan waktu, dan tempat serta membuat janji

c) Langkah awal menentukan fokus permasalahan, membuat pertanyaan-pertanyaan pembuka (bersifat terbuka dan terstruktur) dan mempersiapkan catatan sementara

d) Pelaksanaan melakukan wawancara sesuai dengan persiapan yang dikerjakan

e) Menutup pertemuan

2. Observasi untuk mengumpulkan data yang di perlukan, penelitian mengadakan observasi secara langsung di lapangan. ${ }^{2}$

3. Dokumentasi yaitu teknik pengumpulan dengan menginpestasi dokumen-dokumen yang relapan dan terkait dengan permasalahan yang diteliti. ${ }^{3}$

${ }^{2}$ Ibid, hlm 384

Mohd Iqbal Abdul Muin, Siti Abidah Lubis|

Peran Dinas Sosial dalam Pemberdayaan Masyarakat melalui Program Keluarga Harapan (PKH) untuk Penanggulangan Kemiskinan di Desa Sidiangkat Kecamatan Sidikalang 


\section{Informan Penelitian}

Penetapan informan dalam penelitian ini berdasarkan anggapan bahwa informan dapat memberikan informasi yang diinginkan penelitian sesuai dengan permasalahn penelitian. Informan dalam penelitian ini adalah :

Tabel 1. Informan Penelitian

\begin{tabular}{|c|c|c|c|}
\hline No & Nama & Jabatan/Pekerjaan & Alasan \\
\hline 1 & Drs. Erwin Sihotang & Sekretaris Dinas Sosial & $\begin{array}{l}\text { Karena beliau } r \text { selaku } \\
\text { sekretaris di Dinas Sosial } \\
\text { Kabupaten Dairi yang } \\
\text { mewakili peran Program } \\
\text { Dinas Sosial }\end{array}$ \\
\hline 2 & Bahtra Sigalingging & $\begin{array}{l}\text { Koordinator Program } \\
\text { Keluarga Harapan }\end{array}$ & $\begin{array}{l}\text { Karena beliau selaku } \\
\text { koordinator PKH di } \\
\text { Kabupaten Dairi }\end{array}$ \\
\hline 3 & $\begin{array}{l}\text { Mawardi Tumangger, } \\
\text { S.AP }\end{array}$ & Lurah di Sidiangkat & $\begin{array}{l}\text { Selaku lurah di Sidiangkat } \\
\text { dan dapat memberikan } \\
\text { informan }\end{array}$ \\
\hline 4 & Kurnia Sihotang & Pendamping PKH & $\begin{array}{l}\text { Karena beliau selaku } \\
\text { pendamping } \\
\text { Sidiangkat }\end{array}$ \\
\hline 5 & Meriyati Hutahuruk & Penerima Bantuan PKH & Masyarakat Sidiangkat \\
\hline 6 & Maidah Berutu & Penerima Bantuan PKH & Masyarakat Sidiangkat \\
\hline 7 & Relida Sinaga & Penerima Bantuan PKH & Masyarakat Sidiangkat \\
\hline 8 & Nurhainim Solin & Penerima Bantuan PKH & Masyarakat Sidiangkat \\
\hline 9 & Emeria Banurea & Penerima Bantuan PKH & Masyarakat Sidiangkat \\
\hline 10 & Yenni Pasaribu & Penerima Bantuan PKH & Masyarakat Sidiangkat \\
\hline 11 & Diana & Penerima Bantuan PKH & Masyarakat Sidiangkat \\
\hline 12 & Relida Sinaga & Penerima Bantuan PKH & Masyarakat Sidiangkat \\
\hline
\end{tabular}

${ }^{3}$ Ibid, hlm.391

Mohd Iqbal Abdul Muin, Siti Abidah Lubis|

Peran Dinas Sosial dalam Pemberdayaan Masyarakat melalui Program Keluarga Harapan (PKH) untuk Penanggulangan Kemiskinan di Desa Sidiangkat Kecamatan Sidikalang 


\section{Teknik Analisis Data dan Keabsahan Data}

Analisis data penelitian kualitatif adalah upaya yang dilakukan dengan jelas bekerja dengan data, mengorganisasikannya serta memilamilahnya menjadi satuan yang dapat dikelola, mensistematikannya, mencari dan menentukan pola apa yang penting dan apa yang dipelajari dan memutuskan apa yang dapat diceritakan kepada orang lain.

Adapun teknik keabsahan data penelitian ini menggunakan triangulasi Burhan Bungan menjelaskan bahwa hal ini dapat tercapai dengan cara yaitu :

1. Membandingkan data hasil pengamatan dengan hasil wawancara

2. Membandingkan apa yang dikatakan orang di depan umum dengan apa yang dilakukan secara pribadi

3. Membandingkan dengan apa yang dikatakan orang-orang tentang situasi penelitian dengan apa yang dikatakan sepanjang waktu

4. Membandingkan keadaan dan perspektif seseorang dengan berbagai pendapat dan pandangan orang seperti rakyat biasa, orang yang berpendidikan menengah atau tinggi dan pemenerintahan.

5. Membandingkan hasil wawancara dengan ini suatu dokumen yang berkaitan. ${ }^{4}$

\section{HASIL DAN PEMBAHASAN}

\section{Bentuk Kegiatan Dinas Sosial Dalam Pemberdayaan Masyarakat Melalui Program Keluarga Harapan (PKH)}

Dinas Sosial Kabupaten Dairi yang merupakan lembaga yang bertanggung jawab terhadap penanganan kemiskinan. Masalah sosial kemiskinan ini merupakan fenomena sosial yang tidak bisa dihindari keberadaanya dalam kehidupan masyarakat. untuk meningkatkan efektifitas upaya penanggulangan kemiskinan, pemerintah mengeluarkan Peraturan Presiden No.15 Tahun 2010 tantang Percepatan Penanggulangan Kemiskinan.

Untuk mengetahui lebih lanjut mengenai peran Dinas Sosial dalam pemberdayaan masyarakat melalui Program Keluarga Harapan (PKH) untuk penanggulangan kemiskinan di Desa Sidiangkat Kecamatan Sidikalang Kabupaten Dairi, Drs. Erwin Sihotang sebagai sekretaris di Dinas Sosial mengatakan, Dinas Sosial dalam melaksanakan peranannya mengacu pada Peraturan Presiden No 15. 2010 BAB III Pasal 3 tentang Percepatan Penanggulangan Kemiskinan yaitu untuk mengentaskan beban pengeluaran masyarakat

\footnotetext{
${ }^{4}$ Burhan Bungin, Penelitian Kualitatif, (Jakarta : Prenada Media Group, 2007), hlm. 265

Mohd Iqbal Abdul Muin, Siti Abidah Lubis

Peran Dinas Sosial dalam Pemberdayaan Masyarakat melalui Program Keluarga Harapan (PKH) untuk Penanggulangan Kemiskinan di Desa Sidiangkat Kecamatan Sidikalang 
miskin, meningkatkan kemampuan dan pendapatan masyarakat miskin, mengembangkan dan menjamin keberlanjutan usaha Mikro dan Kecil, dan mensinergikan kebijakan dan program penanggulangan kemiskinan.

Dalam upaya pemberdayaan masyarakat, pemerintah telah melakukan banyak usaha untuk menekan angka kemiskinan diantaranya diadakannya berbagai program pengentasan kemiskinan dan pemberdayaan masyarakat, program tersebut yaitu Program Keluarga Harapan $(\mathrm{PKH})$, didalam PKH ini terdiri dari 3 aspek yaitu PKH bagi pemberi pelayanan kesehatan, PKH bagi pemberi pendidikan, dan $\mathrm{PKH}$ bagi pemberi kesejahteraan sosial.Program Keluarga Harapan ini diberikan kepada rumah tangga sangat miskin (RTSM) ${ }^{5}$

Berdasarkan wawancara yang peneliti lakukan dengan bapak Bahtra Sigalingging selaku koordinator Program Keluarga Harapan Kecamatan Sidikalang mengatakan bahwa bentuk kegiatan Program Keluarga Harapan dalam meningkatkan kesejahteraan masyarakat terdiri dari 3 aspek yaitu: ${ }^{6}$

1. PKH (Program Kelurga Harapan) bagi pemberi pelayanan kesehatan

Tersedianya sarana dan prasarana kesehatan yang memadai merupakan syarat utama yang harus dipenuhi untuk mensukseskan pelaksanaan PKH kesehatan. Kehadiran tenaga kesehatan yang kompeten bukan hanya diperlukan dalam memberikan pelayanan kesehatan bagi peserta PKH, tapi mereka juga dituntut berpartisipasi aktif dalam mensukseskan program PKH kesehatan ini dengan cara :

a. Membimbing peserta PKH untuk memanfaatkan pelayanan kesehatan, seperti datang ke puskesmas atau sarana kesehatan lainnya.

b. Melakukan verifikasi apakah peserta PKH telah memenuhi komitmen yang ditetapkan, seperti rutin memeriksa kehamilan.

c. Memberikan pelayanan kesehatan yang berkualitas kepada keluarga peserta $\mathrm{PKH}$, seperti kesempatan dan kemudahan dalam memeriksakan kesehatan peserta PKH.

Berdasarkan hasil wawancara yang peneliti dengan bapak Bahtra Sigalingging mengatakan, yang mendapatkan PKH kesehatan yaitu rumah tangga sangat miskin (RTSM)

\footnotetext{
${ }^{5}$ Erwin Sihotang, Dinas Sosial "Sekretaris Dinas Sosial" Wawancara Pribadi, Kantor Dinas Sosial, 6 Agustus 2019.

${ }^{6}$ Bahtra Sigalingging, Koordinator PKH "Program Keluarga Harapan", Wawancara Pribadi, Sidikalang, 6 Agustus 2019
} 
RTSM ditetapkan sebagai calon peserta PKH dan akan menerima bantuan komponen kesehatan jika pendataan ditemukan anggota keluarga yang terdiri dari :

a. Ibu Hamil

b. Ibu nifas

c. Anak usia 0-6 tahun

Selanjutnya bapak Bahtra Sigalingging mengatakan, syarat peserta mendapatkan bantuan PKH apabila calon peserta tersebut telah menghadiri pertemuan awal dan atau menandatangani surat perjanjian mematuhi komitmen yang ditetapkan dalam program. RTSM yang terpilih sebagai peserta PKH berhak memperoleh bantuan uang tunai sebesar Rp. $550.000 /$ tahun.

Dan selanjutnya bapak Bahtra Sigalingging juga mengatakan besaran bantuan tunai untuk peserta $\mathrm{PKH}$ bervariasi tergantung jumlah anggota keluarga yang diperhitungkan dalam penerimaan bantuan baik komponen kesehatan maupun pendidikan.

Tabel 2. Besaran Bantuan Kesehatan dan Pendidikan

\begin{tabular}{ll}
\hline \multicolumn{1}{c}{ Indeks Bantuan } & Bantuan Per RTSM/Tahun \\
\hline Bantuan tetap & Rp. 550.000 \\
\hline Bantuan Komponen Kesehatan & \\
1. Ibu Hamil & Rp. 2.400 .000 \\
2. Anak Usia Dini & Rp. 2.400 .000 \\
\hline Bantuan Komponen Pendidikan & \\
1. SD & Rp. 900.000 \\
2. SMP & Rp. 1.500 .000 \\
3. SMA & Rp. 2.000 .000 \\
\hline Bantuan Komponen Kesejahteraan Sosial & \\
1. Disabilitas Berat & Rp. 2.400 .000 \\
2. Lanjut Usia & Rp. 2.400 .000 \\
\hline
\end{tabular}

Selanjutnya bapak Bahtra Sigalingging juga mengatakan, untuk bisa menerima hak peserta PKH harus memenuhi kewajiban atau komitmen yang ditetapkan kewajiban yang dimaksud adalah :

1. Memeriksa kesehatan pada fasilitas pelayanan kesehatan sesuai dengan protokol kesehatan bagi ibu hamil/menyusui dan anak berusia 0 (nol) sampai dengan 6 (enam) tahun. 
2. Mengikuti kegiatan belajar dengan tingkat kehadiran paling sedikit $85 \%$ (delapan puluh lima persen) dari hari belajar efektif bagi anak usia sekolah wajib belajar 12 (dua belas) tahun, dan

3. Mengikuti kegiatan di bidang kesehateraan sosial sesuai dengan kebutuhan bagi keluarga yang memiliki komponen lanjut usia mulai dari 60(enam puluh) tahun dan/atau penyandang disabilitas berat. ${ }^{7}$

Lanjut informan yang sama,

Seperti yang diungkapkan bapak Bahtra Sigalingging, setiap orang yang mendapatkan bantuan program ini, harus melalui beberapa persyaratan yaitu:

\section{Tabel 3 Persyaratan Peserta PKH Kesehatan}

\begin{tabular}{|c|c|}
\hline Sasaran & Persyaratan (kewajiban peserta) \\
\hline Ibu Hamil & $\begin{array}{l}\text { Ibu hamil harus melakukan pemeriksaan } \\
\text { kehamilan di faskes sebanyak minimal } 4 \\
\text { kali selama kehamilan. Melahirkan di } \\
\text { fasilitas pelayanan kesehatan. }\end{array}$ \\
\hline Ibu Nifas & $\begin{array}{l}\text { Pemeriksaan kesehatan ibu nifas } 4 \text { kali } \\
\text { selama } 42 \text { hari setelah melahirkan }\end{array}$ \\
\hline Bayi Usia 0-11 Bulan & $\begin{array}{l}\text { 1. Pemeriksaan kesehatan } 3 \text { kali dalam } 1 \\
\text { bulan pertama } \\
\text { 2. ASI Eksklusif selama } 6 \text { bulan } \\
\text { pertama } \\
\text { 3. Imunisasi lengkap } \\
\text { 4. Penimbangan berat badan dan } \\
\text { pengukuran tinggi badan setiap } \\
\text { bulannya } \\
\text { 5. Mendapat suplemen vit A satu kali } \\
\text { pada usia 6-11 bulan } \\
\text { 6. Pemantauan perkembangan minimal } \\
2 \text { kali dalam setahun }\end{array}$ \\
\hline Usia 1- 5 Tahun & $\begin{array}{l}\text { 1. Imunisasi tambahan } \\
\text { 2. Penimbangan berat badan minimal } 2 \\
\text { kali dalam setahun } \\
\text { 3. Pemantauan perkembangan minimal } \\
2 \text { kali dalam setahun } \\
\text { 4. Pemberian kapsul vit A } 2 \text { kali dalam } \\
\text { setahun }\end{array}$ \\
\hline Usia 5-6 Tahun & 1. Penimbangan berat badan minimal 2 \\
\hline
\end{tabular}

${ }^{7}$ Bahtra Sigalingging, Koordinator PKH “Program Keluarga Harapan”, Wawancara Pribadi, Sidikalang, 6 Agustus 2019 
kali dalam setahun

2. Pengukuran tinggi badan minimal 2 kali dalam setahun

3. Pemantauan perkembangan minimal 2 kali dalam setahun ${ }^{8}$

2. PKH (Program Keluarga Harapan) bagi pemberi pelayanan pendidikan

Komponen pendidikan dalam PKH dikembangkan dalam rangka meningkatkan angka partisipasi pendidikan dasar, khususnya bagi anak anak dari RTSM, serta untuk mengentaskan angka pekerja anak.

Persyaratan yang ditetapkan untuk komponen pendidikan dalam PKH adalah mendaftarkan peserta didik dan memenuhi jumlah kehadiran yang ditetapkan dalam program. Melalui persyaratan untuk mengikuti pendidikan dasar diharapkan PKH akan meningkatkan partisipasi pendidikan dan hal lain mendukung kebijakan pemerintah Indonesia tentang program Wajib Belajar Pendidikan 12 Tahun.

Tersedianya fasilitas dan pelayanan pendidikan (seperti sekolah, tenaga pendidik) yang memadai merupakan syarat utama yang harus dipenuhi untuk mensukseskan tujuan pelaksanaan PKH dalam komponen pendidikan. Ketersediaan tenaga pendidik (guru, pamong, tutor) yang kompeten bukan hanya diperlukan dalam memberikan pengajaran saja, mereka juga dituntut harus berkontribusi aktif dalam mensukseskan pelaksanaan PKH komponen pendidikan, yaitu melalui keterlibatan untuk memberikan pendidikan yang berkualitas serta melakukan verifikasi komitmen kehadiran anak-anak peserta PKH di kelas. ${ }^{9}$

Menurut bapak Bahtra Sigalingging, untuk mendapatkan bantuan PKH Pendidikan ini, ada sasaran dan persyaratan untuk mendapatkan bantuan tersebut, yaitu: ${ }^{10}$

Table 4. Persyaratan Peserta PKH Pendidikan

\begin{tabular}{lll}
\hline \multicolumn{1}{c}{ Sasaran } & \multicolumn{1}{c}{ Persyaratan } \\
\hline $\begin{array}{l}\text { Usia 6-21 Tahun yang belum } \\
\text { menyelesaikan pendidikan dasar } \\
\text { (SD,SMP,SMA) }\end{array}$ & 1. & $\begin{array}{l}\text { Terdaftar di sekolah/pendidikan } \\
\text { kesetaraan }\end{array}$ \\
\hline
\end{tabular}

8 Tim Penyusun PKH, 2019, Pedoman Operasional PKH Bagi Pemberi Pelayanan Kesehatan, 9 Desember.

${ }^{9}$ Tim Penyusun PKH, 2019, Pedoman Operasional PKH Bagi Pemberi Pelayanan Pendidikan, 9 Desember.

${ }^{10}$ Bahtra Sigalingging, Koordinator PKH "Program Keluarga Harapan", Wawancara Pribadi, Sidikalang, 6 Agustus 2019 
3. PKH (Program Keluarga Harapan) bagi pemberi pelayanan kesejahteraan sosial Table IV

Komponen kesejahteraan sosial dibagi menjadi 2 yaitu disabilitas berat dan lansia 60 tahun ke atas.Berikut ini adalah penjelasan tentan pelayanan kepada kesejahteraan sosial.

a. Disabilitas Berat

Pihak keluarga atau pengurus melayani, merawat, dan memastikan pemeriksaan kesehatan bagi penyandang disabilitas berat minimal 1 tahun sekali dengan menggunkan

1. Layanan home visit (tenaga kesehatan datang ke rumah (Keluarga Penerima Manfaat) KPM penyandang disabilitas berat)

2. Layanan home care (pengurus memandikan, mengurus, dan merawat KPM PKH)

b. Lansia 60 Tahun ke atas

1. Memastikan pemeriksaaan kesehatan

2. Serta penggunaan layanan puskesmas santun lanjut usia

3. Layanan home care (pengurus merawat, memandikan, dan mengurusi KPM lanjut usia)

4. Day care (mengikuti kegiatan sosial di lingkungan tempat tinggal, lari pagi, senam sehat, dan lain sebagainya) bagi lanjut usia tersebut minimal 1 tahun sekali. ${ }^{11}$

Berdasarkan penelitian yang peneliti lakukan, bapak Bahtra Sigalingging mengatakan, jumlah keseluruhan bantuan yang di dapatkan oleh peserta PKH Tahun 2019 di Sidiangkat yaiu ${ }^{12}$

Tabel 5. Jumlah Bantuan PKH Tahun 2019 di Sidiangkat

\begin{tabular}{ccc}
\hline Kategori & Jumlah Peserta & $\begin{array}{c}\text { Jumlah Bntuan Dalam } \\
\text { Rupiah }\end{array}$ \\
\hline $\begin{array}{c}\text { Tahap I } \\
\text { (Januari) }\end{array}$ & 138 Peserta & Rp. 230.625.000 \\
\hline $\begin{array}{c}\text { Tahap II } \\
\text { (April) }\end{array}$ & 137 Peserta & Rp. 154.225.000 \\
\hline $\begin{array}{c}\text { Tahap III } \\
\text { (Juli) }\end{array}$ & 137 Peserta & Rp. 158.350.000 \\
\hline
\end{tabular}

${ }^{11}$ Tim Penyusun PKH, 2019, Pedoman Operasional PKH Bagi Pemberi Pelayanan Kesejahteraan Sosisal, 9 Desember.

${ }^{12}$ Bahtra Sigalingging, Koordinator PKH "Program Keluarga Harapan", Wawancara Pribadi, Sidikalang, 6 Agustus 2019 
Berikut ini merupakan hasil wawancara dengan peserta yang memperoleh bantuan PKH (Program Keluarga Harapan).

Berdasarkan wawancara yang peneliti lakukan dengan ibu Meriyati Hutahuruk selaku peserta PKH, dengan adanya bantuan PKH yang diberikan ini dinilai sangat bermanfaat dan membantu perekonomian keluarga, karenapenghasilan yang diterima oleh suaminya sebagai petani yang terkadang tidak tetap dan dengan adanya PKH maka beban kesehatan dan pendidikan anak-anaknya menjadi terbantu. ${ }^{13}$

Selanjutnya wawancara dengan Ibu Maidah Berutu selaku peserta PKH, dengan adanya bantuan PKH yang diberikan ini dinilai sangat membantu bagi perekonomian keluarganya, karena penghasilannya dari tani terkadang tidak tetap dan dengan adanya PKH maka beban kesehatan dan pendidikan anak-anaknya menjadi terbantu. ${ }^{14}$

Selanjutnya wawancara dengan Ibu Relida Sinaga selaku peserta $\mathrm{PKH}$, dengan adanya bantuan PKH yamh diberikan ini dinilai sangat membantu bagi perekonomian keluarganya, karena penghasilan yang diterima oleh suaminya sebagai petani yang terkadang tidak tetap dan dengan adanya PKH maka beban kesehatan dan pendidikan anak-anaknya menjadi terbantu. $^{15}$

Selanjutnya wawancara dengan Ibu Nurhainim Solin selaku peserta $\mathrm{PKH}$, dengan adanya bantuan PKH yang diberikan ini dinilai sangat membantu bagi perekonomian keluarganya, karena penghasilan yang diterima oleh suaminya sebagai supir yang terkadang tidak tetap dan dengan adanya bantuan PKH, maka beban pendidikan anak-anaknya dan kesehatan menjadi terbantu. ${ }^{16}$

Selanjutnya wawancara dengan Ibu Emeria Banurea selaku peserta $\mathrm{PKH}$, dengan adanya bantuan PKH yang diberikan ini dinilai sangat membantu bagi perekonomian keluarganya, karena penghasilan yang diterima suaminya sebagai petani yang terkadang tidak

\footnotetext{
${ }^{13}$ Meriyati Hutahuruk, Masyarakat Sidiangkat "Penerima Bantuan PKH”Wawancara Pribadi, Sidiangkat, 13 Agustus 2019

14 Maidah Berutu, Masyarakat Sidiangkat "Penerima Bantuan PKH" Wawancara Pribadi, Sidiangkat, 13 Agustus 2019

${ }_{15}$ Relida Sinaga, Masyarakat Sidiangkat "Penerima Bantuan PKH" Wawancara Pribadi, Sidiangkat, 13 Agustus 2019

${ }^{16}$ Nurhainim Solin, Masyarakat Sidiangkat "Penerima Bantuan PKH" Wawancara Pribadi, Sidiangkat, 13 Agustus 2019
} 
tetap dan dengan adanya PKH maka beban kesehatan dan pendidikan anak-anaknya terbantu. ${ }^{17}$

Dan selanjutnya wawancara dengan Ibu Yenni Pasaribu selaku peserta PKH, dengan adanya bantuan PKH yang diberikan ini dinilai sangat membantu bagi perekonomian keluarganya, karena penghasilan suaminya sebagai supir yang terkadang tidak tetap dan dengan adanya PKH maka beban kesehatan dan pendidikan anak-anaknya menjadi terbantu. ${ }^{18}$

\section{Hambatan Pemerintah Dalam Pelaksanaan PKH (Program Keluarga Harapan)}

Berdasarkan hasil wawancara yang peneliti teliti dengan Bapak Mawardi Tumangger S.AP selaku lurah dikelurahan di Desa Sidinagkat, mengatakan hambatan yang ada dalam melaksanakan Program Keluarga Harapan ini adalah pendataan jumlah masyarakat yang kurang mampu yang belum lengkap.Itu disebabkan banyaknya masyarakat yang tidak melaporkan data ketidakmampuan mereka kekelurahan, sehingga menjadi kendala bagi kelurahan dalam pendataan penduduk yang kurang mampu sehingga masyarakat yang seharusnya mendapatkan program bantuan ini malah tidak mendapatkan, serta masyarakat pun masih kurang memahami dengan bantuan Program Keluarga Harapan ini. ${ }^{19}$

Selanjutnya berdasarkan hasil waancara dengan Bapak Kurnia Sihotang selaku pendamping Program Keluarga Harapan Kecamatan Sidikalang Desa Sidiangkat mengatakan bahwa kendala yang menjadi hambatan pemerintah selama ini dalam pelaksanaan Program Keluarga Harapan ini adalah Pendataan Kependudukan Masyarakat Miskin yang menerima PKH (Program Keluarga Harapan). ${ }^{20}$

Sedangkan dari Pihak Dinas Sosial sendiri hambatan yang ditemukan dalam melaksanakan Program Keluarga Harapan (PKH) adalah :

1. Masalah Closing Data Masyarakat Miskin

2. Verifikasi Data untuk Anak Sekolah

3. Kelengkapan Data Masyarakat yang Kurang lengkap seperi KTP dan Kartu Keluarga

\footnotetext{
17 Emeria Banurea, Masyarakat Sidiangkat "Penerima Bantuan PKH" Wawancara Pribadi, Sidiangkat, 13 Agustus 2019

${ }^{18}$ Yenni Pasaribu, Masyarakat Sidiangkat "Penerima Bantuan PKH" Wawancara Pribadi, Sidiangkat, 13 Agustus 2019

${ }^{19}$ Mawardi Tumangger, Lurah Desa Sidiangkat "Hambatan Pelaksanaan PKH" Wawancara Pribadi, 13 Agustus 2019

${ }^{20}$ Kurnia Sihotang, Pendamping PKH "Hambatan Pelaksanaan PKH" Wawancara Pribadi, 12 Agustus 2019
} 
4. Data yang kurang lengkap dari peserta anak yang menerima bantuan pendidikan dan kesehatan

5. Kurangnya pemahaman masyarakat mengenai keberadaan $\mathrm{PKH} .{ }^{21}$

Berdasarkan wawancara yang peneliti lakukan dengan Ibu Meriyati Hutahuruk salah satu masyarakat yang mendapatkan bantuan Program Keluarga Harapan ini mengatakan hambatan yang ada pada pelaksanaan Program Keluarga Harapan ini adalah banyaknya warga disini yang tidak tahu akan adanya bantuan-bantuan dari pemerintah sehingga kurangnya pemahaman masyarakat miskin terhadap adanya bantuan Program Keluarga Harapan ini sehingga masyarakat yang seharusnya mendapatkan bantuan PKH ini menjadi tidak dapat merasakan manfaat dari bantuan PKH. Ini menyebabkan banyak masyarakat miskin yang tidak mengurus data kemiskinannya karena mereka mengira tidak ada bantuan dari pemerintah yang akan mensejahterakan mereka. ${ }^{22}$

Sama halnya juga dengan Ibu Maidah dan Ibu Diana menurutnya hambatan yang ada pada pelaksanaan PKH ini banyaknya warga di Desa Sidiangkat ini yang tidak mengetahui akan adanya bantuan dari pemerintah dalam Bentuk Program Keluarga Harapan, sehingga kurangnya pemahaman masyarakat terhadap Program Keluarga Harapan. ${ }^{23}$

\section{Solusi Pemerintah Dalam Pelaksanaan PKH (Program Keluarga Harapan)}

Berdasarkan wawancara yang peneliti lakukan dengan Bapak Mawardi Tumangger S.AP selaku lurah di Desa Sidiangkat mengatakan solusi yang harus dilakukan agar Program Keluarga Harapan ini dapat berjalan dengan lancar dan mensejahterakan masyarakat dihimbaukan kepada masyarakat masyarakat miskin untuk melaporkan kepada kekelurahan data kemiskinannya sehingga akan mempermudah pemerintah dan program-programnya untuk mendapatkan data. Dan masyarakat juga harus melakukan pendekatan dan pemahaman akan adanya Program Keluarga Harapan dan dari pihak PKH sendiri pun harus terjun langsung kelapangan dan menginformasikan kepada masyarakat agar masyarakt dapat

\footnotetext{
${ }^{21}$ Erwin Sihotang, Sekretaris Dinas Sosial "Hambatan Pelaksanaan PKH" Wawancara Pribadi, 7 Agustus 2019

${ }^{22}$ Meriyati Hutahuruk, Masyarakat Sidiangkat "Hambatan Pelaksanaan PKH" Wawancara Pribadi, 13 Agustus 2019

${ }^{23}$ Maida dan Diana, Masyarakat Sidiangkat "Hambatan Pelaksanaan PKH" Wawancara Pribadi, 13 Agustus 2019
} 


\section{JURNAL PEMBERDAYAAN MASYARAKAT $\mid 107$ \\ Volume 8 No. 1 Tahun 2020 ISSN: 2355-8679}

memahami Program Keluarga Harapan ini sehingga membantu pemerintah dalam mensejahterakan masyarakat. ${ }^{24}$

Selanjutnya berdasarkan hasil waancara dengan Erwin Sihotang selaku sekretaris dinas sosial Kecamatan Sidikalang Kabupaten Dairi mengatakan solusi yang dilakukan agar tidak terjadi hambatan dalam melaksanakan Program Dinas Sosial Melalui Keluarga Harapan ini adalah:

1. Pemerintah sendiri melalui BPS (Badan Pusat Statistik) untuk dapat melakukan pendataan kembali kepada masyarakat miskin agar bantuan Program Keluarga Harapan ini dapat dirasakan dan dimanfaatkan oleh masyarakat miskin sehingga terciptalah kesejahteraan bagi masyarakat.

2. Masyarakat harus melengkapi data-datanya untuk menjadi peserta Program Keluarga Harapan sehingga masyarakat miskin dapat memperoleh bantuan dari Program Keluarga Harapan.

3. Pemerintah hendaknya menambah nilai bantuan dan jumlah penerimaan bantuan PKH (Program Keluarga Harapan).

4. Masyarakat harus melakukan pendekatan dan pemahaman akan adanya program pemerintah dalam bentuk Program Keluarga Harapan (PKH). ${ }^{25}$

Disamping itu menurut Ibu Meriyati Hutahuruk dan Relida Sinaga solusi dalam pelaksanaan PKH ini agar dapat berjalan dengan lancar dan manfaatnya dapat dirasakan masyarakat miskin, masyarakat harus lebih memahami akan adanya program bantuan pemerintah dalam bentuk PKH dan dari pihak pemerintah supaya makin sering kelapangan untuk menginformasikan kepada masyarakat tentang Program Keluarga Harapan. ${ }^{26}$

Menurut Ibu Diana Angkat dan Ibu Maidah Berutu solusi dalam pelaksanaan PKH ini agar dapat berjalan dengan baik masyarakat juga harus lebih memahami akan adanya bantuan

24 Mawardi Tumangger, Lurah Desa Sidiangkat, "Solusi dalam Pelaksanaan PKH" Wawancara Pribadi, 13 Agustus 2019

${ }^{25}$ Erwin Sihotang, Sekretaris Dinas Sosial,"Solusi dalam PKH" Wawancara Pribadi, 6 Agustus 2019

${ }^{26}$ Meriyati Hutahuruk dan Relida Sinaga, Masyarakat Sidiangkat, " Solusi dalam PKH” Wawancara Pribadi, 13 Agustus 2019 
dari Program Keluarga Harapan dan pemerintah juga supaya makin sering survei langsung kelapangan. $^{27}$

\section{KESIMPULAN}

Kehadiran dan peranan Dinas Sosial melalui Program Keluarga Harapan (PKH) di Desa Sidiangkat Kecamatan Sidikalang Kabupaten Dairi ternyata memberikan kesejahteraan bagi masyarakat Desa Sidiangkat. Berdasarkan penelitain yang yang dilakukan di Desa Sidiangkat Kecamatan Sidikalang Kabupaten Dairi berjalan sesuai dengan tujuannya untuk mengentaskan kemiskinan dan meningkatkan kualitas sumber daya manusia pada kelompok masyarakat sangat miskin dengan memberikan pelayanan kesehatan, pelayanan pendidikan, dan pelayanan kesejahteraan sosial kepada masyarakat yang miskin. Setelah di diteliti ternyata kesehatan dan pendidikan memiliki hubungan yang sangat erat dan berpengaruh terhadap kemiskinan dan kualitas sumber daya manusia apabila kondisi kesehatan dan pendidikan masyarakat rendah maka akan berpengaruh terhadap tingkat pendapatan masyarakat oleh karena itu dengan adanya Progran Keluarga Harapan masyarakat miskin di Desa Sidiangkat menjadi sangat terbantu.

Dalam meningkatkan kesejahteraan masyarakat, pemerintah mengalami beberapa hambatan dalam pemberdayaan masyarakat melalui Program Keluarga Harapan diantaranya adalah pendataan kependudukan masyarakat miskin yang tidak lengkap sehingga menjadi kendala bagi pihak PKH dalam meratakan pemberian penerima bantuan $\mathrm{PKH}$, kurangnya pemahaman masyarakat mengenai Program Keluarga Harapan.

Adapun solusi pemerintah dalam meningkatkan kesejahteraan masyarakat dalam pelaksanaan Program Keluarga Harapan adalah pemerintah melalui BPS (Badan Pusat Statistik) melakukan pendataan ulang kepada masyarakat miskin agar program bantuan ini dapat dapat dirasakan dan dimanfaatkan oleh masyarakat miskin sehingga terwujudlah kesejahteraan masyarakat, dan masyarakat harus melakukan pendekatan dan pemahaman akan adanya Program Keluarga Harapan dan dati tim Program Keluarga Harapan juga harus terjun kelapangan dan memberikan arahan kepada masyarakat yang tidak paham akan adanya Program Keluarga Harapan.

\footnotetext{
${ }^{27}$ Diana dan Relida, , Masyarakat Sidiangkat, “ Solusi dalam PKH” Wawancara Pribadi, 13 Agustus 2019 


\section{DAFTAR PUSTAKA}

Abdul Syani, 1995, Sosiologi dan Perubahan Masyarakat, Lampung : Pustaka Jaya

Ahmad Mustofa al-Maraghi, 1998, Terjemah Tafsir al-Maraqhi, Semarang : CV Toha Putra

Burhan Bungin,2007, Penelitian Kualitatif, Jakarta : Prenada Media Group

Dasril Arifin, Penelitian, 2013 : "Peran Dinas Sosial Terhadap Penanggulangan Angka Kemiskinan Di Kabupaten Siak" Pekanbaru : UIN Sultan Syarif Kasim

Departemen Pendidikan dan Kebudayaan, 1998, Kamus Besar Bahasa Indonesia, Jakarta : Balai Pustaka

Edy Suharto, 2005, Membangun Masyarakat Memberdayakan Rakyat, Bandung : Adimata

Elly M. Setiadi dan Usman Kolip, 2015, Pengantar Sosiologi, Jakarta: Prenadamedia Group

Elly M. Setiadi dan Usman Kolip,2015, Pengantar Sosiologi, Jakarta: Prenadamedia Group

Fredian Tonny, 2014, Pengembangan Masyarakat, Jakarta: Yayasan Pustaka Obor Indonesia

https://prasfapet.wordpress.com/2015/05/07/konsep-dan-teori-pemberdayaan-masyarakat/ (diakses 05 Juli 2015, pukul 11:40)

Irma Irawan, Penelitian, 2012 :"Peranan Program Keluarga Harapan (PKH) Dalam Meningkatkan Kesejahteraan Masyarakat Islam Di Kelurahan Belawan Bahagia Kecamatan Medan Belawan” Medan,IAIN SU

Munandar Soelaeman, 1986, Ilmu Sosial Dasar teori dan Konsep Ilmu Sosial, Bandung: Refika Saditama

Muri Yusuf,2017, Metode Penelitian,Jakarta:Kencana

Owin Jamasy 2004,, Keadilan Pemberdayaan Penanggulangan Kemiskinan, Jakarta : Belantika

Parsudi Suparlan, 1995, Kemiskinan di Perkotaan, Jakarta: Sinar Harapan

Permensos No 1 tahun 2018, Program Keluarga Harapan BAB II Hak Dan Kewajiban Keluarga Penerima Manfaat PKH

Soerjono Soekanto, 2010, Sosiologi Suatu Pengantar, Jakarta : Rajagrafindo Persada

Tim Penyusun PKH, 2019, Pedoman Operasional PKH Bagi Pemberi Pelayanan Kesehatan, Jakarta

Tim Penyusun PKH, 2019, Pedoman Operasional PKH Bagi Pemberi Pelayanan Pendidikan, Jakarta

Tim Penyusun PKH, 2019, Pedoman Operasional PKH Bagi Pemberi Pelayanan Kesejahteraan Sosial, Jakarta

Totok Mardikanto \& Poerwoko Soebianto2017, Pemberdayaan Masyarakat, Bandung: Alfabets

Zubaidi, 2013 “Pengembangan Masyarakat”, Jakarta : PT Kharisma Putra Utama 